\title{
Effect of salmeterol/fluticasone combination on the dynamic changes of lung mechanics in mechanically ventilated COPD patients: a prospective pilot study
}

This article was published in the following Dove Press journal:

International Journal of COPD

27 January 2016

Number of times this article has been viewed

\section{Wei-Chih Chen ${ }^{1,2}$ \\ Hung-Hsing Chen ${ }^{2}$ \\ Chi-Huei Chiang ${ }^{2}$ \\ Yu-Chin Lee ${ }^{3}$ \\ Kuang-Yao Yang ${ }^{1,2}$}

'Institute of Emergency and Critical Care Medicine, School of Medicine, National Yang-Ming University, Taipei,

Taiwan; ${ }^{2}$ Department of Chest Medicine, Taipei Veterans General Hospital, Taipei, Taiwan; ${ }^{3}$ Sijhih Cathay General Hospital, Taipei, Taiwan
Correspondence: Kuang-Yao Yang Department of Chest Medicine, Taipei Veterans General Hospital, No 20I, Section 2, Shih-Pai Road, Taipei II217, Taiwan

Tel +8862 28757456

Fax +88622875 7610

Email kyyang@vghtpe.gov.tw
Background: The combined therapy of inhaled corticosteroids and long-acting beta- 2 agonists for mechanically ventilated patients with COPD has never been explored. Therefore, the aim of this study was to investigate their dynamic effects on lung mechanics and gas exchange.

Materials and methods: Ten mechanically ventilated patients with resolution of the causes of acute exacerbations of COPD were included. Four puffs of salmeterol $25 \mu \mathrm{g} /$ fluticasone $125 \mu \mathrm{g}$ combination therapy were administered. Lung mechanics, including maximum resistance of the respiratory system (Rrs), end-inspiratory static compliance, peak inspiratory pressure (PIP), plateau pressure, and mean airway pressure along with gas exchange function were measured and analyzed.

Results: Salmeterol/fluticasone produced a significant improvement in Rrs and PIP after 30 minutes. With regard to changes in baseline values, salmeterol/fluticasone inhalation had a greater effect on PIP than Rrs. However, the therapeutic effects seemed to lose significance after 3 hours of inhaled corticosteroid/long-acting beta-2 agonist administration.

Conclusion: The combination of salmeterol/fluticasone-inhaled therapy in mechanically ventilated patients with COPD had a significant benefit in reducing Rrs and PIP.

Keywords: COPD, inhaled corticosteroid, long-acting beta- 2 agonist, mechanical ventilation, respiratory failure

\section{Introduction}

In patients with moderate-to-severe COPD, treatment with a combination of an inhaled long-acting beta-2 agonist (LABA), and an inhaled corticosteroid (ICS) has been shown to be more effective than the individual components in reducing exacerbations and improving lung function and health status. ${ }^{1-4}$ In addition, the use of systemic corticosteroid treatment along with other therapies has been recommended for the management of hospitalized patients with acute exacerbations of COPD. ${ }^{4-6} \mathrm{~A}$ previous study demonstrated that in patients in a stable condition with severe COPD and chronic hypercapnic respiratory failure, a brief period of inhaled fluticasone treatment may produce a short-acting bronchodilator response, mainly related to a reduction in airway resistance, that is not detected by the usual pulmonary function tests. ${ }^{7}$ However, the combined therapy of an inhaled LABA and ICS is not yet recommended as a standard therapy for patients with COPD during acute exacerbations or for those with a chronic stable status requiring mechanical ventilatory support. Therefore, the aim of this study was to evaluate the short-term effect of inhaled salmeterol/fluticasone therapy on dynamic changes in lung mechanics and gas exchange in mechanically ventilated patients with acute exacerbations of COPD in whom the causes of acute 
respiratory failure are under control, but who are not yet ready to be weaned from mechanical ventilation.

\section{Materials and methods Study design and patients}

This prospective cohort study was conducted at a 24-bed respiratory intensive care unit of Taipei Veterans General Hospital, a tertiary medical center in Taiwan. From August 2007 to November 2007, ten consecutive mechanically ventilated patients with an acute exacerbation of COPD as defined by the Global initiative for chronic Obstructive Lung Disease guidelines were enrolled. The inclusion criteria were subjects with a well-established diagnosis of COPD who were endotracheally intubated and mechanically ventilated. In addition, the causes of acute respiratory failure were under control in these patients, but they were not yet ready to have the mechanical ventilatory support withdrawn. Further, all of the included patients had stable vital signs, fraction concentration of inspired oxygen $\left(\mathrm{FiO}_{2}\right)$ less than $40 \%$, and had not used long-acting bronchodilators, including oral, intravenous, or inhaled forms for at least 48 hours. None of the patients had received systemic corticosteroid therapy or a tapering of systemic corticosteroids to oral prednisolone less than $20 \mathrm{mg}$ per day. The exclusion criteria included patients with persistent exacerbations, which required the use of intravenous or oral corticosteroid therapy of more than prednisolone $20 \mathrm{mg}$ per day. In addition, patients with other severe clinically significant medical disorders besides COPD such as congestive heart failure, New York Heart Association Functional Classification III-V, liver cirrhosis, Child-Pugh score $\mathrm{C}$, or chronic renal failure were also excluded, as were patients with a diagnosis of bronchial asthma, pneumonia, pulmonary edema, refractory hypoxemia, pneumothorax, or excessive airway secretions. The study protocol was approved by the Institutional Review Board of Taipei Veterans General Hospital and was conducted in accordance with the Declaration of Helsinki. Written informed consent was obtained from all participants or their authorized representatives before enrollment.

\section{Protocol}

Oral systemic corticosteroids were withheld in the early morning before the study began, and the protocol was performed for all subjects at a similar time in the morning. Careful sputum suction using an open method and preoxygenation with $100 \%$ $\mathrm{FiO}_{2}$ were performed before the initiation of the protocol and 5 minutes before each measurement. This time interval has been shown to be sufficient to avoid the effects of a transient bronchoconstrictive response to suction. ${ }^{8}$ The ventilator was maintained in the volume-control mode during the whole study (3 hours) with tidal volume $\leq 8 \mathrm{~mL} / \mathrm{kg}$, flow rate $50-60 \mathrm{~L} / \mathrm{min}, \mathrm{FiO}_{2} \leq 40 \%$, and positive end-expiratory pressure $\leq 5 \mathrm{~cm} \mathrm{H}_{2} \mathrm{O}$. All of the subjects were sedated with intravenous short-acting anesthesia (midazolam), which was assessed by the absence of spontaneous breathing efforts. Before the use of hydrofluoroalkane pressurized metered-dose inhalers (HFA pMDIs) with a combination of salmeterol and fluticasone (Seretide ${ }^{\circledR} 125$ Evohaler, containing salmeterol $25 \mu \mathrm{g}$ and fluticasone $125 \mu \mathrm{g}$ per puff, GlaxoSmithKline, Brentford, UK), six parameters were measured as baseline values, including maximum resistance of the respiratory system (Rrs), end-inspiratory static compliance of the respiratory system (Crs, st), peak inspiratory pressure (PIP), plateau pressure (Pplat), mean airway pressure (MAP), and gas exchange function (partial pressure of oxygen in arterial blood $\left(\mathrm{PaO}_{2}\right)$ versus $\mathrm{FiO}_{2}, \mathrm{PaO}_{2} / \mathrm{FiO}_{2}$ ratio). In the ventilator circuit, salmeterol/fluticasone inhalation was delivered via an AeroVent ${ }^{\circledR}$ (Monaghan Medical Corporation, Plattsburgh, NY, USA) device on the inspiratory limb with one puff per breath for four consecutive breaths during inspiration. The canister was shaken before each series of puffs.

\section{Measurement of lung mechanics}

All patients were examined in a semirecumbent position with the head of the bed up to $30^{\circ}$. During the protocol, a physician not involved in the study was always present to provide care for the patients. Lung mechanics were measured using the monitor and program setting of the mechanical ventilator (SERVO 300 ventilator, Siemens, Munich, Germany). Five parameters were measured to evaluate changes in lung mechanics, including Rrs, Crs, st, PIP, Pplat, and MAP, all of which were measured at the bedside, and the ratio of $\mathrm{PaO}_{2} / \mathrm{FiO}_{2}$. We used the occlusion technique as previously described to measure lung mechanics. ${ }^{9,10}$

All of the lung mechanics parameters were measured at baseline, and then 30 minutes, 1, 2, and 3 hours after salmeterol/fluticasone inhalation, at which times sputum suction was carefully performed. Arterial blood gas was analyzed at baseline, 1, and 3 hours after inhalation, and each sampling was performed before sputum suction. The setting of the ventilator was not changed during the whole course of the protocol, and all patients were kept in a ventilatordependent state with the use of sedatives.

\section{Statistical analysis}

Measurements concerning the overall effects of salmeterol/ fluticasone inhalation on lung mechanics and gas exchange 
Table I Patient characteristics and baseline arterial blood gas

\begin{tabular}{lllllll}
\hline Age (years) & $\mathrm{FEV}_{1}(\mathrm{~L})$ & $\mathrm{FiO}_{2}$ & $\mathrm{pH}$ & $\mathrm{PaCO}_{2}(\mathbf{m m H g})$ & $\mathbf{H C O}_{3}{ }^{-}(\mathbf{m m H g})$ & $\mathbf{P a O}_{2}(\mathbf{m m H g})$ \\
\hline $81 \pm 4.1$ & $1.16 \pm 0.18$ & $0.33 \pm 0.07$ & $7.44 \pm 0.06$ & $27.9 \pm 5.4$ & $18.8 \pm 5.9$ & $104.2 \pm 19.6$ \\
\hline
\end{tabular}

Note: Data are presented as mean \pm SD.

Abbreviations: $\mathrm{FEV}_{1}$, force expiratory volume in I second; $\mathrm{FiO}_{2}$, fractional concentration of inspired oxygen; $\mathrm{PaCO}$, partial pressure of arterial carbon dioxide; $\mathrm{PaO}$, partial pressure of arterial oxygen; SD, standard deviation.

function were analyzed using a nonparametric Wilcoxon signed rank test. Statistical analysis was performed using SPSS 19.0 software (Statistical Package for the Social Sciences, Chicago, IL, USA). The primary endpoints were changes in lung mechanics, including Rrs, Crs, st, PIP, Pplat, and MAP. The secondary endpoint was a change in gas exchange function. A $P$-value $<0.05$ was considered to be statistically significant for all tests.

\section{Results}

\section{Patient characteristics and lung mechanics measured at different time points in ventilated COPD patients who received salmeterol/fluticasone inhalation}

All of the enrolled patients completed the study, and their characteristics are shown in Table 1. The causes of acute respiratory failure were all due to COPD with secondary infections (ten cases). The COPD stages of the ten patients were moderate (three patients) to severe (seven patients), according to the Global initiative for chronic Obstructive Lung Disease guidelines. No specific side effects were noted during the combination therapy with salmeterol/fluticasone inhalation. Table 2 shows the mean values and standard deviations of respiratory mechanics recorded at the different time points. The changes in Rrs, PIP, and MAP are shown in Figure 1. Two patients showed no obvious bronchodilator responses to the combination therapy with salmeterol/ fluticasone, and in the remaining eight patients, the mean Rrs change from baseline was $7.9 \% \pm 8.7 \%$ at 30 minutes, reaching a peak decrease of $16.5 \% \pm 10.6 \%$ at 2 hours. Figure 2 shows individual values of Rrs during the study period.

\section{Changes in maximum resistance of the Rrs in the ventilated COPD patients with salmeterol/fluticasone inhalation}

As shown in Figure 3, a significant reduction in airway resistance was observed after 30 minutes of combination therapy with salmeterol/fluticasone (baseline, $17.4 \pm 7.6 \mathrm{~cm}$ $\mathrm{H}_{2} \mathrm{O} / \mathrm{L} / \mathrm{s} ; 30$ minutes, $16.3 \pm 7.4 \mathrm{~cm} \mathrm{H}_{2} \mathrm{O} / \mathrm{L} / \mathrm{s}, P=0.043 ; 1$ hour, $15.8 \pm 7.4 \mathrm{~cm} \mathrm{H}_{2} \mathrm{O} / \mathrm{L} / \mathrm{s}, P=0.018 ; 2$ hours, $14.9 \pm 6.7 \mathrm{~cm}$ $\mathrm{H}_{2} \mathrm{O} / \mathrm{L} / \mathrm{s}, P=0.011 ; 3$ hours, $16.4 \pm 7.6 \mathrm{~cm} \mathrm{H}_{2} \mathrm{O} / \mathrm{L} / \mathrm{s}, P=0.116$ ). The lowest value of airway resistance was noted at 2 hours, and at 3 hours airway, resistance was not significantly different from baseline, although a trend of a reduction was still observed.

\section{Effect of salmeterol/fluticasone inhalation in PIP}

As shown in Figure 4, a significant reduction in PIP was observed after 30 minutes of therapy (baseline, $29.8 \pm 7.6 \mathrm{~cm}$ $\mathrm{H}_{2} \mathrm{O} ; 30$ minutes, $26.4 \pm 6.1 \mathrm{~cm} \mathrm{H}_{2} \mathrm{O}, P=0.018$; 1 hour, $24.3 \pm 5.6 \mathrm{~cm} \mathrm{H}_{2} \mathrm{O}, P=0.005 ; 2$ hours, $23.9 \pm 5.8 \mathrm{~cm} \mathrm{H}_{2} \mathrm{O}$, $P=0.005 ; 3$ hours, $27.2 \pm 7.8 \mathrm{~cm} \mathrm{H}_{2} \mathrm{O}, P=0.028$ ).

\section{Gas exchange after salmeterol/fluticasone inhalation}

As shown in Figure 5, no obvious improvement in the ratio of $\mathrm{PaO}_{2}$ and $\mathrm{FiO}_{2}$ was observed 1 or 3 hours after treatment

Table 2 Lung mechanics before and up to 3 hours after salmeterol/fluticasone inhalation

\begin{tabular}{|c|c|c|c|c|c|}
\hline $\begin{array}{l}\text { Parameters for } \\
\text { lung mechanics }\end{array}$ & Baseline & 30 minutes & I hour & 2 hours & 3 hours \\
\hline $\operatorname{Rrs}\left(\mathrm{cm} \mathrm{H}_{2} \mathrm{O} / \mathrm{L} / \mathrm{s}\right)$ & $17.4 \pm 7.6$ & $16.3 \pm 7.4^{\mathrm{a}}$ & $15.8 \pm 7.4^{a}$ & $14.9 \pm 6.7^{\mathrm{a}}$ & $16.4 \pm 7.6$ \\
\hline $\mathrm{Crs}$, st $\left(\mathrm{mL} / \mathrm{cm} \mathrm{H} \mathrm{H}_{2} \mathrm{O}\right)$ & $46.0 \pm 23.6$ & $45.3 \pm 23.5$ & $45.0 \pm 23.7$ & $45.2 \pm 23.7$ & $45.3 \pm 23.8$ \\
\hline PIP $\left(\mathrm{cm} \mathrm{H}_{2} \mathrm{O}\right)$ & $29.8 \pm 7.6$ & $26.4 \pm 6.1^{\mathrm{a}}$ & $24.3 \pm 5.6^{\mathrm{a}}$ & $23.9 \pm 5.8^{\mathrm{a}}$ & $27.2 \pm 7.8^{\mathrm{a}}$ \\
\hline Pplat $\left(\mathrm{cm} \mathrm{H} \mathrm{H}_{2} \mathrm{O}\right)$ & $23.1 \pm 10.2$ & $21.2 \pm 7.1$ & $19.9 \pm 5.0$ & $21.7 \pm 5.5$ & $23.5 \pm 9.9$ \\
\hline $\operatorname{MAP}\left(\mathrm{cm} \mathrm{H}_{2} \mathrm{O}\right)$ & $12.3 \pm 3.4$ & $12.2 \pm 3.5$ & $11.3 \pm 3.2^{\mathrm{a}}$ & $10.9 \pm 3.2^{\mathrm{a}}$ & $11.4 \pm 3.5$ \\
\hline $\mathrm{PaO}_{2} / \mathrm{FiO}_{2}$ & $328.0 \pm 83.8$ & NA & $374.7 \pm 97.8$ & NA & $331.3 \pm 87.8$ \\
\hline
\end{tabular}

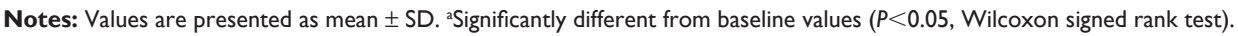

Abbreviations: $\mathrm{Crs}$, st, end-inspiratory static compliance of the respiratory system; MAP, mean airway pressure; NA, not applicable; $\mathrm{PaO}_{2} / \mathrm{FiO}_{2}$, partial pressure of oxygen in arterial blood/fraction concentration of inspired oxygen; PIP, peak inspiratory pressure; Pplat, plateau pressure; Rrs, maximum resistance of the respiratory system; $\mathrm{SD}$, standard deviation. 


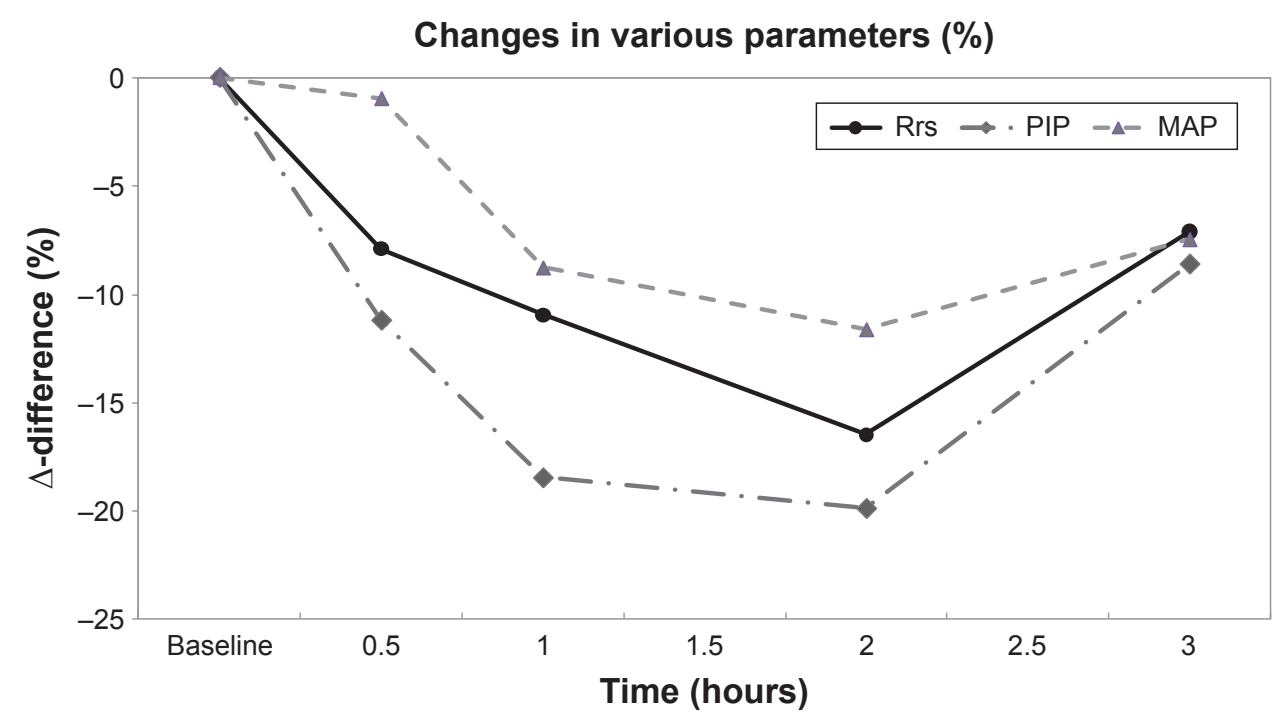

Figure I Percent changes ( $\Delta$-difference \%) in peak inspiratory pressure (PIP), mean airway pressure (MAP), and maximum resistance of the respiratory system (Rrs). Note: Changes were observed after the use of combination therapy with salmeterol/fluticasone inhalation.

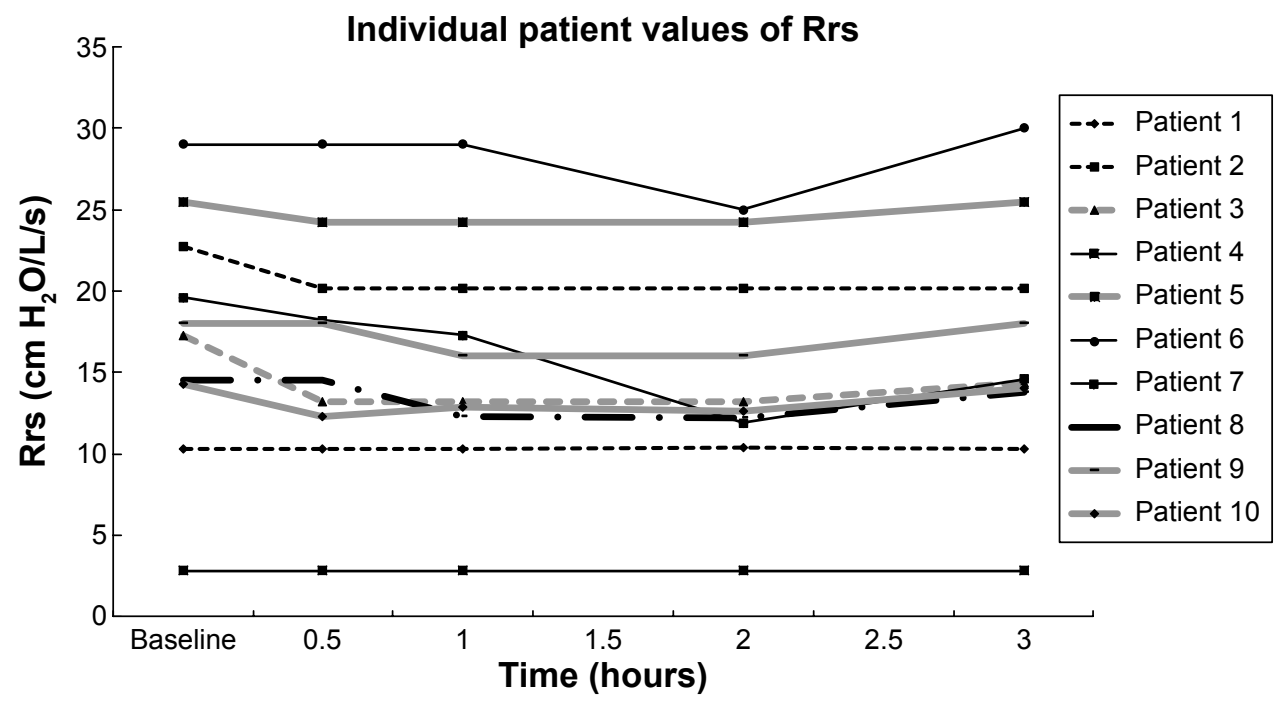

Figure 2 Individual patient values of maximum resistance of the respiratory system (Rrs).

Note: Reduction in airway resistance was observed 30 minutes after salmeterol/fluticasone treatment.

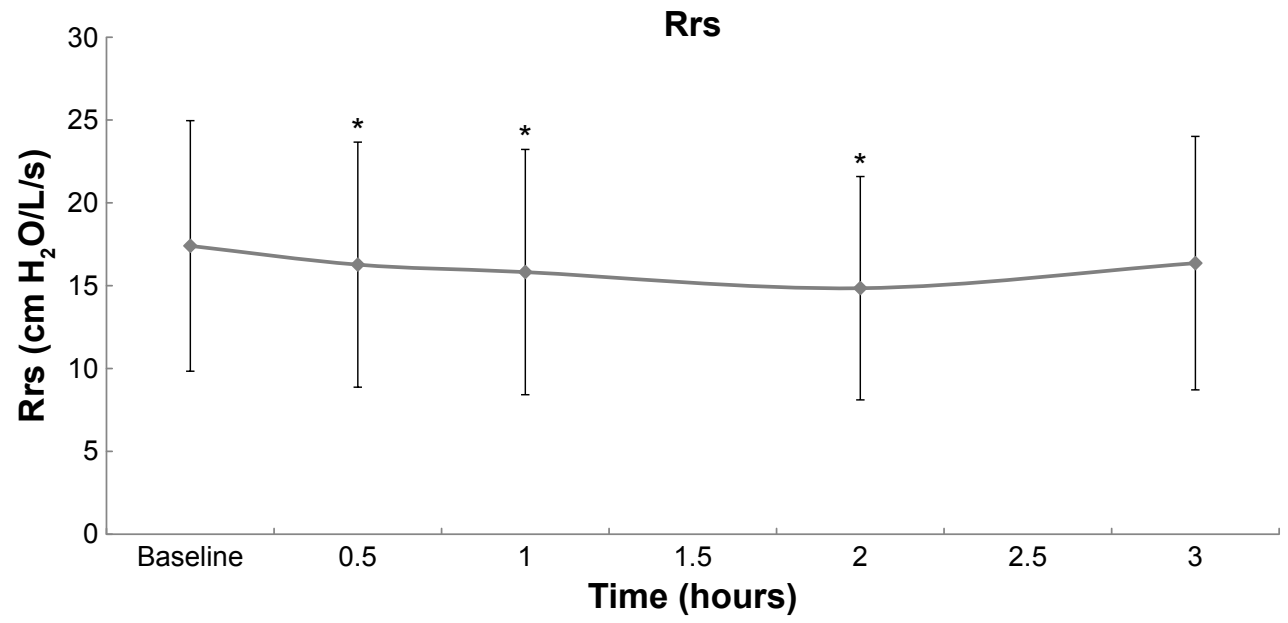

Figure 3 Effect of combination therapy with salmeterol/fluticasone inhalation on maximum resistance of the respiratory system (Rrs) mean values.

Notes: Mean values \pm SD of airway resistance at baseline and up to 3 hours. *Significantly different from baseline values $(P<0.05$, Wilcoxon signed rank test).

Abbreviation: SD, standard deviation. 


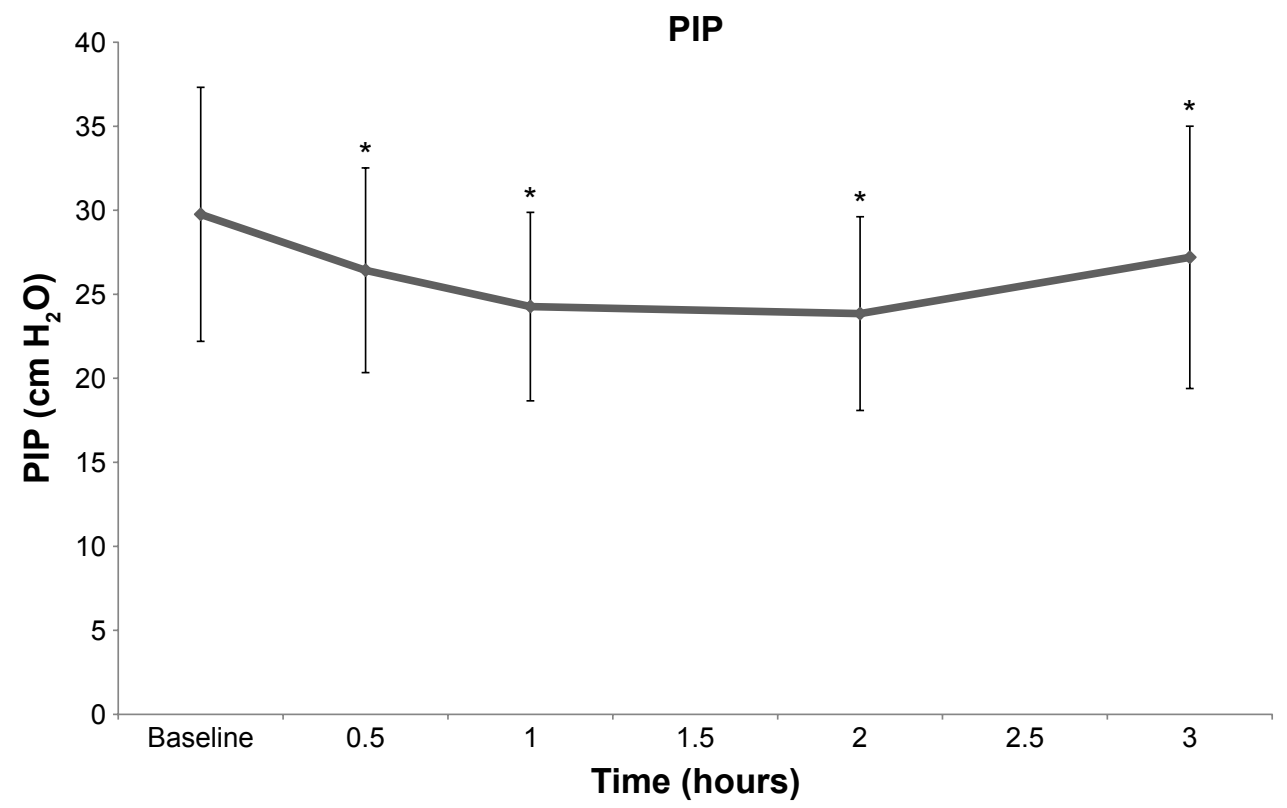

Figure 4 Effect of combination therapy with salmeterol/fluticasone inhalation on peak inspiratory pressure mean values.

Notes: Mean values \pm SD of peak inspiratory pressure at baseline and up to 3 hours. *Significantly different from baseline values $(P<0.05$, Wilcoxon signed rank test).

Abbreviations: SD, standard deviation; PIP, peak inspiratory pressure.

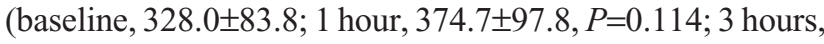
$331.3 \pm 87.8, P=0.847)$.

\section{Discussion}

In this study, combination therapy using $100 \mu \mathrm{g}$ salmeterol and $500 \mu \mathrm{g}$ fluticasone inhalation delivered by MDIs with a spacer provided a significant improvement in lung mechanics, as expressed by a reduction in maximum resistance of the Rrs, PIP, and MAP in the short term. No obvious improvement in oxygenation after the combination therapy was noted. To the best of our knowledge, this is the first study to examine the effect of combination therapy with a
LABA and ICS on lung mechanics in mechanically ventilated COPD patients.

The use of bronchodilators with a MDI and spacer has been reported to have a similar effect and duration compared with nebulizers in mechanically ventilated COPD patients. ${ }^{11,12}$ Several studies have shown that short-acting beta-2 agonists cause a significant decrease in airway resistance in COPD patients under mechanical ventilation. ${ }^{13,14}$ However, only a few studies have reported the use of inhaled long-acting bronchodilators ${ }^{15}$ or $\mathrm{ICSs}^{7}$ in such patients. Malliotakis et al reported that salmeterol caused a significant decrease in dynamic and static airway pressure and also minimum and

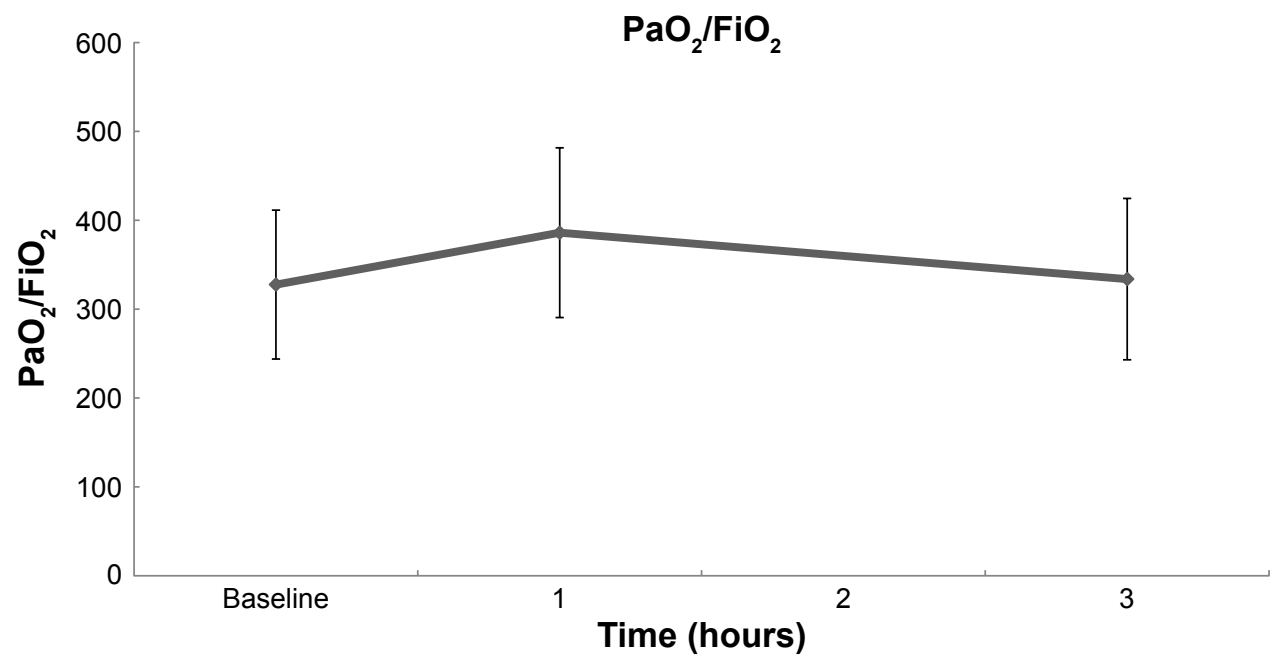

Figure 5 Effect of combination therapy with salmeterol/fluticasone inhalation on $\mathrm{PaO}_{2} / \mathrm{FiO}_{2}$ mean values.

Note: Mean values $\pm \mathrm{SD}$ of mean $\mathrm{PaO}_{2} / \mathrm{FiO}_{2}$ at baseline and up to 3 hours.

Abbreviations: $\mathrm{PaO}_{2} / \mathrm{FiO}_{2}$, partial pressure of oxygen in arterial blood/fraction concentration of inspired oxygen; SD, standard deviation. 
maximum inspiratory resistance in mechanically ventilated patients with acute exacerbations of COPD. ${ }^{15}$ Similar to their results, we observed improvements in lung mechanics after 30 minutes of inhaled salmeterol/fluticasone treatment. However, the peak effect of this therapy appeared after 2 hours of drug administration. After 3 hours, except for a persistently significant reduction in PIP compared with baseline, there were no significant differences in other parameters including airway resistance and MAP from baseline.

Several factors may contribute to these differences in results. First, our cases were all Asians, not Caucasians. Second, the mean age of our patients was 81 years, which is much older than in the other study. Third, our patients were relatively stable in terms of underlying etiology of acute respiratory failure being controlled, as demonstrated by a lower dosage of systemic steroids (prednisolone less than $20 \mathrm{mg}$ per day). As with lung mechanics, our patients had lower airway resistance and PIP at baseline.

Previous studies have reported that beta- 2 adrenergic receptor agonists cause a transient decrease in $\mathrm{PaO}_{2}$ in spite of concomitant bronchodilation ${ }^{16-20}$ through a pulmonary arterial vasodilation effect by activation of beta-adrenoceptors, which are present in pulmonary vessels, thereby causing an increase in pulmonary blood flow to poorly ventilated lung regions and worsening ventilation-perfusion inequality. ${ }^{21,22}$ Furthermore, adding an ICS with a LABA has been reported to improve oxygenation compared with a LABA alone as ICSs can acutely decrease bronchial blood flow. ${ }^{16}$ This effect may be caused by the capability of corticosteroids to interrupt the uptake of noradrenaline by smooth muscle cells of human bronchial arteries (extraneural uptake: uptake2). This then increases the noradrenaline concentration at $\alpha$-adrenergic receptor sites of bronchial vascular smooth muscle cells that explains corticosteroid-induced vasoconstriction. ${ }^{23}$ This effect may change the blood flow from poorly ventilated alveoli to better ventilated areas, thereby improving the matching of ventilation and perfusion and maintaining an adequate $\mathrm{PaO}_{2} \cdot{ }^{24}$ Interestingly, it has been shown that uptake2 is inhibited by steroid hormones through a nongenomic action in vitro. ${ }^{25}$ This nongenomic action occurs within seconds to a few minutes, ${ }^{26}$ and this could explain why the protective action of fluticasone on the vascular effect of salmeterol is immediate. Our results also support this hypothesis.

The combination of an ICS and LABA is increasingly used as maintenance therapy in patients with moderate-tosevere COPD. ${ }^{27,28}$ The effect of ICSs is thought to be mediated through suppression of airway inflammation, while LABAs are thought to work by inducing bronchodilation. Increasing evidence indicates that these two classes of drugs interact positively with each other, leading to added or perhaps synergistic benefits for patients. Corticosteroids enhance the expression of beta-2 adrenoceptors, thus providing protection against desensitization and the development of tolerance to beta- 2 adrenoceptor agonists, which may occur with the prolonged use of these medications. LABAs, on the other hand, may amplify the anti-inflammatory effects of corticosteroids by accelerating nuclear translocation of the glucocorticoid receptor complex, and enhancing the transcription and expression of steroid-inducible genes in proinflammatory cells.

In previous clinical trials, inhaled salmeterol/fluticasone propionate $50 / 500$ and $25 / 250 \mu$ g treatment twice daily was shown to result in significant increases in pre- and postdose forced expiratory volume in 1 second and improvements from baseline compared to a placebo in patients with moderateto-severe COPD. ${ }^{3,29,30}$ In addition, forced expiratory volume in 1 second 2 hours postdose was shown to improve significantly more with salmeterol/fluticasone propionate $50 / 500$ or $50 / 250 \mu \mathrm{g}$ than with a placebo or fluticasone propionate in a 24-week trial. ${ }^{30}$ Furthermore, another study reported an improvement in symptoms within 1 week with salmeterol/ fluticasone propionate treatment twice daily. ${ }^{31}$

The major limitations of this study include the short study period and small sample size. Some methodological issues should also be discussed. First, only a single dose of combination therapy with salmeterol/fluticasone inhalation was given. Second, only ten patients were included in the study; however, several similar studies have also enrolled the same number of patient to investigate the effect of single dose inhalation. ${ }^{7,15}$ In addition, the lack of a placebo group may be another limitation; however, a placebo for a pMDI inhaler is difficult to find in Taiwan. Our enrolled cases were mechanically ventilated patients with acute exacerbations of COPD with the causes of acute respiratory failure under control. ICSs may be necessary to control airway inflammation in this population; however, having a comparison group with LABA therapy alone may raise ethical concerns. Therefore, further studies are needed to validate our results in patients with acute respiratory failure due to COPD who are receiving mechanical ventilation.

In this study, we used salmeterol/fluticasone combination therapy with a HFA pMDI instead of using a salmeterol HFA pMDI and fluticasone HFA pMDI separately. There are several reasons for this. First, only salmeterol chlorofluorocarbon (CFC) MDIs and fluticasone CFC MDIs are available in Taiwan. The ozone-depleting potential of CFCs has been well documented and they have mainly been replaced by 
HFA products. Second, many studies have shown that HFA pMDIs are pharmacokinetically and clinically comparable to or even superior to traditional CFC MDIs. ${ }^{32-37}$

Further studies are needed to evaluate the effects on lung mechanics in patients with COPD and respiratory failure requiring mechanical ventilation and multiple doses of combination therapy with salmeterol/fluticasone inhalation. In addition, a larger study population may also be necessary to confirm these findings with regard to the benefits of combination therapy.

\section{Conclusion}

Salmeterol/fluticasone inhalation therapy in patients with COPD and mechanical ventilation showed significant beneficial effects in reducing Rrs and PIP.

\section{Acknowledgment}

This work was supported by Taiwan MOST Research Grant MOST 103-2314-B-075-049-MY2 and Taipei Veterans General Hospital Grants V102C-025, V103C-078, and V104C-038.

\section{Disclosure}

The authors report no conflicts of interest in this work.

\section{References}

1. Mahler DA, Wire P, Horstman D, et al. Effectiveness of fluticasone propionate and salmeterol combination delivered via the Diskus device in the treatment of chronic obstructive pulmonary disease. Am J Respir Crit Care Med. 2002;166(8):1084-1091.

2. Calverley PM, Anderson JA, Celli B, et al. Salmeterol and fluticasone propionate and survival in chronic obstructive pulmonary disease. $N$ Engl J Med. 2007;356(8):775-789.

3. Calverley P, Pauwels R, Vestbo J, et al. Combined salmeterol and fluticasone in the treatment of chronic obstructive pulmonary disease: a randomised controlled trial. Lancet. 2003;361(9356):449-456.

4. Vestbo J, Hurd SS, Agusti AG, et al. Global strategy for the diagnosis, management, and prevention of chronic obstructive pulmonary disease: GOLD executive summary. Am J Respir Crit Care Med. 2013;187(4): 347-365.

5. Davies L, Angus RM, Calverley PM. Oral corticosteroids in patients admitted to hospital with exacerbations of chronic obstructive pulmonary disease: a prospective randomised controlled trial. Lancet. 1999; 354(9177):456-460.

6. Niewoehner DE, Erbland ML, Deupree RH, et al. Effect of systemic glucocorticoids on exacerbations of chronic obstructive pulmonary disease. Department of Veterans Affairs Cooperative Study Group. NEngl J Med. 1999;340(25):1941-1947.

7. Nava S, Compagnoni ML. Controlled short-term trial of fluticasone propionate in ventilator-dependent patients with COPD. Chest. 2000; 118(4):990-999.

8. Guglielminotti J, Desmonts JM, Dureuil B. Effects of tracheal suctioning on respiratory resistances in mechanically ventilated patients. Chest. 1998;113(5):1335-1338.

9. Rossi A, Gottfried SB, Higgs BD, Zocchi L, Grassino A, Milic-Emili J. Respiratory mechanics in mechanically ventilated patients with respiratory failure. J Appl Physiol. 1985;58(6):1849-1858.
10. Bates JH, Rossi A, Milic-Emili J. Analysis of the behavior of the respiratory system with constant inspiratory flow. J App Physiol. 1985; 58(6):1840-1848.

11. Duarte AG, Momii K, Bidani A. Bronchodilator therapy with metereddose inhaler and spacer versus nebulizer in mechanically ventilated patients: comparison of magnitude and duration of response. Respir Care. 2000;45(7):817-823.

12. Holland A, Smith F, Penny K, McCrossan G, Veitch L, Nicholson C. Metered dose inhalers versus nebulizers for aerosol bronchodilator delivery for adult patients receiving mechanical ventilation in critical care units. Cochrane Database Syst Rev. 2013;6:CD008863.

13. Mouloudi E, Katsanoulas K, Anastasaki M, Askitopoulou E, Georgopoulos D. Bronchodilator delivery by metered-dose inhaler in mechanically ventilated COPD patients: influence of end-inspiratory pause. Eur Respir J. 1998;12(1):165-169.

14. Malliotakis P, Mouloudi E, Prinianakis G, Kondili E, Georgopoulos D. Influence of respiratory efforts on b2-agonist induced bronchodilation in mechanically ventilated COPD patients: a prospective clinical study. Respir Med. 2007;101(2):300-307.

15. Malliotakis P, Linardakis M, Gavriilidis G, Georgopoulos D. Duration of salmeterol-induced bronchodilation in mechanically ventilated chronic obstructive pulmonary disease patients: a prospective clinical study. Crit Care. 2008;12(6):R140.

16. Cazzola M, Noschese P, De Michele F, D’Amato G, Matera MG. Effect of formoterol/budesonide combination on arterial blood gases in patients with acute exacerbation of COPD. Respir Med. 2006;100(2):212-217.

17. Gross NJ, Bankwala Z. Effects of an anticholinergic bronchodilator on arterial blood gases of hypoxemic patients with chronic obstructive pulmonary disease. Comparison with a beta-adrenergic agent. Am Rev Respir Dis. 1987;136(5):1091-1094.

18. Karpel JP, Pesin J, Greenberg D, Gentry E. A comparison of the effects of ipratropium bromide and metaproterenol sulfate in acute exacerbations of COPD. Chest. 1990;98(4):835-839.

19. Khoukaz G, Gross NJ. Effects of salmeterol on arterial blood gases in patients with stable chronic obstructive pulmonary disease. Comparison with albuterol and ipratropium. Am J Respir Crit Care Med. 1999;160(3): 1028-1030.

20. Santus P, Centanni S, Morelli N, Di Marco F, Verga M, Cazzola M. Tiotropium is less likely to induce oxygen desaturation in stable COPD patients compared to long-acting beta2-agonists. Respir Med. 2007;101(8): 1798-1803.

21. Cazzola M, Mantero A, Santus P, et al. Doppler echocardiographic assessment of the effects of inhaled long-acting beta2-agonists on pulmonary artery pressure in COPD patients. Pulm Pharmacol Ther. 2007; 20(3):258-264.

22. Wagner PD, Dantzker DR, Iacovoni VE, Tomlin WC, West JB. Ventilation-perfusion inequality in asymptomatic asthma. Am Rev Respir Dis. 1978;118(3):511-524.

23. Horvath G, Lieb T, Conner GE, Salathe M, Wanner A. Steroid sensitivity of norepinephrine uptake by human bronchial arterial and rabbit aortic smooth muscle cells. Am J Respir Cell Mol Biol. 2001;25(4):500-506.

24. Salvi SS. Alpha1-adrenergic hypothesis for pulmonary hypertension. Chest. 1999;115(6):1708-1719.

25. Losel R, Wehling M. Nongenomic actions of steroid hormones. Nat Rev Mol Cell Biol. 2003;4(1):46-56.

26. Cato AC, Nestl A, Mink S. Rapid actions of steroid receptors in cellular signaling pathways. Sci STKE. 2002;2002(138):re9.

27. Sin DD, Man SF. Corticosteroids and adrenoceptor agonists: the compliments for combination therapy in chronic airways diseases. Eur J Pharmacol. 2006;533(1-3):28-35.

28. Nannini LJ, Poole P, Milan SJ, Holmes R, Normansell R. Combined corticosteroid and long-acting beta(2)-agonist in one inhaler versus placebo for chronic obstructive pulmonary disease. Cochrane Database Syst Rev. 2013;11:CD003794.

29. Fenton C, Keating GM. Inhaled salmeterol/fluticasone propionate: a review of its use in chronic obstructive pulmonary disease. Drugs. 2004;64(17):1975-1996. 
30. Hanania NA, Darken P, Horstman D, et al. The efficacy and safety of fluticasone propionate (250 microg)/salmeterol (50 microg) combined in the Diskus inhaler for the treatment of COPD. Chest. 2003; 124(3):834-843.

31. Szafranski W, Cukier A, Ramirez A, et al. Efficacy and safety of budesonide/formoterol in the management of chronic obstructive pulmonary disease. Eur Respir J. 2003;21(1):74-81.

32. Singh D, Tutuncu A, Lohr I, Carlholm M, Polanowski T. Budesonide administered using chlorofluorocarbon and hydrofluoroalkane pressurized metered-dose inhalers: pharmacokinetics, pharmacodynamics and clinical equivalence. Int J Clin Pharmacol Ther. 2007; 45(9):485-495.

33. Kempsford R, Handel M, Mehta R, De Silva M, Daley-Yates P. Comparison of the systemic pharmacodynamic effects and pharmacokinetics of salmeterol delivered by CFC propellant and non-CFC propellant metered dose inhalers in healthy subjects. Respir Med. 2005;99(Suppl A): S11-S19.
34. Chopra N, Williams M, Rimmer M, Kahl L, Jenkins M. Salmeterol HFA is as effective as salmeterol CFC in children and adults with persistent asthma. Respir Med. 2005;99(Suppl A):S1-S10.

35. Grzelewska-Rzymowska I, Malolepszy J, de Molina M, Sladek K, Zarkovice J, Siergiejko Z. Equivalent asthma control and systemic safety of inhaled budesonide delivered via HFA-134a or CFC propellant in a broad range of doses. Respir Med. 2003;97(Suppl D):S10-S19.

36. Micheletto C, Guerriero M, Tognella S, Dal Negro RW. Effects of HFA- and CFC-beclomethasone dipropionate on the bronchial response to methacholine (MCh) in mild asthma. Respir Med. 2005; 99(7):850-855.

37. Leach CL, Colice GL. A pilot study to assess lung deposition of HFAbeclomethasone and CFC-beclomethasone from a pressurized metered dose inhaler with and without add-on spacers and using varying breathhold times. J Aerosol Med Pulm Drug Deliv. 2010;23(6):355-361.

\section{Publish your work in this journal}

The International Journal of COPD is an international, peer-reviewed journal of therapeutics and pharmacology focusing on concise rapid reporting of clinical studies and reviews in COPD. Special focus is given to the pathophysiological processes underlying the disease, intervention programs, patient focused education, and self management protocols.

\section{Dovepress}

This journal is indexed on PubMed Central, MedLine and CAS. The manuscript management system is completely online and includes a very quick and fair peer-review system, which is all easy to use. Visit $\mathrm{http}: / / \mathrm{www}$. dovepress.com/testimonials.php to read real quotes from published authors.

Submit your manuscript here: http://www.dovepress.com/international-journal-of-chronic-obstructive-pulmonary-disease-journal 